\title{
Optimum Conditions for Extraction of Antibacterial Compounds from Citrus Aurantifolia Fruit Peel Waste
}

\author{
Rima Munawaroh \\ Faculty of Pharmacy, Universitas Muhammadiyah Surakarta \\ Jl. A. Yani Tromol Pos I Pabelan Kartasura 57102 \\ e-mail: rima.munawaroh@ums.ac.id
}

\begin{abstract}
Citrus fruit peel is a major waste in citrus fruit processing industry. The research on extraction active compounds of Citrus aurantifolia (lime) fruit peel waste and antibacterial activity assay has been done. The aim of research was to get optimum condition to extract their active compounds which have antibacterial activity. The dried lime fruit peel was extracted by maceration method using ethanol 48\%, 72\%, and 96\%. The dried and fresh lime fruit peel were also extracted using ethyl acetate. Antibacterial assay was done by diffusion agar against Staphylococcus aureus ATCC 25923 and Escherichia coli ATCC 25922. The result showed that optimal condition to extract antibacterial compound using fresh sample with ethyl acetate as solvent. The ethyl acetate extract of fresh sample was more active against $S$. aureus than E. coli.
\end{abstract}

Keywords: extraction, antibacterial, Citrus aurantifolia, fruit peel

\section{Introduction}

Citrus aurantifolia (lime) cultivated throughout the world, especially in hot subtropical or tropical area (Morton, 1987). The main commercial products are lime juice and essential oils (Chamblee et al., 1997) but the essential oil has economic value is much higher than the juice (Bates et al., 2001). Pectin from citrus fruit peel has also been produced and used as a gelling agent in food products and stabilizer in the beverage product (May, 1990).

Citrus fruit peel is a major waste in juice and citrus essential oil industry because fruit peel consisting of flavedo, albedo, membranes, and pulp occupies between $50-65 \%$ of total weight of citrus. If no further processing it will be waste and causes serious environmental pollution. Therefore industry is interested in improving commercial value of this waste (Bocco et al., 1998).

In addition to essential oils and pectins, citrus fruit peel also contains carotenoids, coumarins, furanocoumarins, and typical citrus flavonoids (flavanone, flavanone glycosides, polimethoxyflavone) (Agocs et al., 2007; Dugo et al., 1999; Li et al., 2006). Lime peel (the flavedo and albedo) contains the main flavonoid hesperidin $(258 \mathrm{mg} / 100$ $\mathrm{g}$ fresh fruit peel) (Nogata et al., 2006). Neohesperidin, flavanones glycosides are just different sugar groups attached to the $\mathrm{C}-7$ than hesperidin, have antibacterial activity against $S$. aureus and E. coli with MIC more than 1 $\mathrm{mg} / \mathrm{ml}$ (Mandalari et al., 2007).

Ethanol $56 \%$ is the best solvent for extracting total flavonoids from dried lime peel powder count as hesperidin (total flavonoid content 3.46\%) (Mujahid, 2011). Ethanolic extract $40 \%, 96 \%$ of whole dried fruit lime has antibacterial activity against $S$. aureus with MIC $32-64 \mathrm{mg} / \mathrm{ml}$ and $E$. coli with MIC 64-256 mg/ml (Aibinu et al., 2007).

The aim of research was to get optimum condition to extract antibacterial compounds from lime fruit peel. The dried lime fruit peel was extracted by maceration method using ethanol 48\%, 72\%, and 96\%. The dried and fresh lime fruit peel were also extracted using ethyl acetate. Antibacterial assay was done by diffusion agar.

\section{Research Methodology}

\section{Materials}

Materials used are lime fruits were taken from Temanggung, Central Java (harvested in January 2011); ethanol, ethyl acetate, distilled water (technical); Escherichia coli ATCC (American Type Culture Collection) 25922 dan Staphylococcus aureus ATCC 25923 (collection of Laboratory of Microbiology, Faculty of Pharmacy UMS); BHI medium 
(CONDA Pronadisa), MH Agar (Oxoid); chloramphenicol $30 \mu \mathrm{g} /$ disc, paper discs with diameter of $6 \mathrm{~mm}$ (Oxoid), DMSO (dimethyl sulfoxide) (Merck); McFarland Equivalence Turbidity Standards 0.5 (Remel), $0.9 \% \mathrm{NaCl}$ (Merck).

\section{Equipments}

Equipments used are rotary evaporator (Heidolph efficient Laborota 4000), waterbath (Memmert), analytical scales, oven (Memmert), vortex, autoclave (Portable Pressure Steam Sterilizer, China), oven (Memmert), LAF (Laminar Air Flow), shaker incubator (Excella 24 New Brunswick scientific), incubator, ruler.

\section{Stages of Research}

Identification of citrus fruit. Identification of fruit was carried out in Pharmaceutical Biology Division, Faculty of Pharmacy, Gadjah Mada University, Yogyakarta based on morphologic characteristics in determination literature. The species of citrus fruit is Citrus aurantifolia (Christm. \& Panz. Swingle), familia Rutaceae.

Preparation of fresh and dried lime fruit peel. Lime peel fruit that were used include flavedo, albedo, segment, and pulp or whole fruit after juices and seeds were taken. Citrus fruit washed, cut, squeezed the juice by hand; fresh peel dipped into the water one time, drained, cut into small pieces and blended. ] Fresh lime fruit peel dried in oven at $41-43^{\circ} \mathrm{C}$ until easily broken, blended, and sieved 10/40 mesh.

Extraction of lime fruit peel. Dried fruit peel extracted with ethanol 48\%, 72\%, 96\% and ethyl acetate; fresh fruit peel extracted with ethyl acetate (table 1). These fruit peel macerated for 24 hours 3 times (each time with new solvent) and stirred occasionally. Liquid extract was filtered, collected, and evaporated with a vacuum rotary evaporator at $45-50{ }^{\circ} \mathrm{C}$ and then continued by waterbath at $60^{\circ} \mathrm{C}$ until a thick extract obtained.
Table 1. Lime fruit peel and solvent used in extraction

\begin{tabular}{|c|c|c|}
\hline Dried peel & \multicolumn{2}{|c|}{ Solvent } \\
\hline $20 \mathrm{~g}$ & $\begin{array}{l}\text { Ethanol 48\% } \\
\text { (ethanol 96\%:a }\end{array}$ & (ethanol 96\%:aquadest $=1: 1 \mathrm{v} / \mathrm{v}$ ) \\
\hline $20 \mathrm{~g}$ & (ethanol 96\%:aquadest $=3: 1 \mathrm{v} / \mathrm{v}$ ) & $\begin{array}{c}150 \mathrm{ml} \\
\mathrm{st}=3: 1 \mathrm{v} / \mathrm{v})\end{array}$ \\
\hline $20 \mathrm{~g}$ & Ethanol $96 \%$ & $150 \mathrm{ml}$ \\
\hline $1122,3 \mathrm{~g}$ & Ethanol 96\% & $12900 \mathrm{ml}$ \\
\hline $300 \mathrm{~g}$ & Ethyl acetate & $3400 \mathrm{ml}$ \\
\hline Fresh peel & \multicolumn{2}{|c|}{ Solvent } \\
\hline $590,26 \mathrm{~g}$ & Ethyl acetate & $2950 \mathrm{ml}$ \\
\hline
\end{tabular}

Diffusion test (Kirby Bauer disc diffusion).Preparation of $S$. aureus and E.coli inoculum with growth method (Wanger, 2007): At least 3-5 well-isolated colonies with the same morphological type were selected from an overnight culture on $\mathrm{MH}$ agar plate. Top of each colony was touched with a sterile loop and transferred into a tube containing 4-5 $\mathrm{ml}$ of BHI medium and incubated in a shaker incubator at $37^{\circ} \mathrm{C}, 200 \mathrm{rpm}$ until its turbidity the same as or exceeded turbidity of $0.5 \mathrm{Mc}$ Farland (usually 2-3 hours) and then bacterial turbidity was adjusted to turbidity of $0.5 \mathrm{Mc}$ Farland standard using sterile $0.9 \% \mathrm{NaCl}(1-2$ x $10^{8} \mathrm{CFU} / \mathrm{ml}$ bacteria population).

Inoculation on agar plate (Wanger, 2007): Inoculum suspension was used within 15 minutes after turbidity adjustment. Two hundred micro liter of bacterial suspension was inoculated on MH Agar plate by spreader glass (thickness of Agar $\pm 4 \mathrm{~mm}$ ).

Extract test solution made with concentrations of 50,100,150, 200, $400 \mathrm{mg} /$ $\mathrm{ml} \mathrm{DMSO;} \mathrm{loading} \mathrm{test} \mathrm{solution} 10 \mu \mathrm{l} /$ disc or equal to $500,1000,1500,2000,4000 \mu \mathrm{g} / \mathrm{disc}$.

Discs application on inoculated agar plates (Wanger, 2007): Paper discs were impregnated with a series concentration of test solutions (extract) and allowed to dry for \pm 30 minutes and then each disc (including positive control disc/antibiotic) was placed on inoculated plates. Plates were left for 15 minutes so that substances in paper discs 
diffuse into plates and then incubated in inverted position (upside down) either aerobically $\left(37^{\circ} \mathrm{C}\right.$ for $16-18$ hours. Diameter of clear zone around discs was measured using a ruler to the nearest millimeter.

\section{Results and Discussions}

Fresh lime fruit peel occupies $52.47 \%$ of the total weight of lime fruit, when all the fruit peel is used after the juices and seeds taken. Lime fruit peel contains essential oils so the fruit peels are dried in oven at $43-45^{\circ} \mathrm{C}$ and obtained $14.41 \%$ dried lime fruit peel powder.

Dried lime fruit reduced in size in order to increase the surface area and facilitate solvent into plant cells thereby enhancing the extraction process. Maceration chosen as the method of extraction because of the cold extraction method, so that less stable compounds in heating is no damage relatively. Saturation of the solvent avoided by stirring and remaceration with new solvent, so the active compound more extracted. Liquid extract is evaporated at temperature less than or equal to $60^{\circ} \mathrm{C}$ so thermolabile compounds are not degraded. Yield of dried lime fruit peel ethanolic extract with ethanol $48 \%$, $72 \%$, and $96 \%$ are $25.10 \%, 24.10 \%, 20.60 \%$ respectively.

Dried lime fruit peel ethanolic extract $48 \%, 72 \%, 96 \%$ dried on loading 500, 1000, $1500 \mu \mathrm{g} / \mathrm{disc}$ does not inhibit S.aureus. Improved loading of ethanolic extract $96 \%$ to 2000 and $4000 \mu \mathrm{g} /$ disc inhibit S.aureus with inhibition zone diameter $6.3 \mathrm{~mm}$ and $8.5 \mathrm{~mm}$ respectively. Ethanolic extract $96 \%$ inhibit S.aureus in a large loading (4000 $\mu \mathrm{g} /$ disc), therefore we try using the ethyl acetate extract of dried and fresh lime fruit peel, because of essential oil and less polar compounds in fruit peel.Yield of dried and fresh lime fruit peel ethyl acetate extract are $8.11 \%$ and $1.84 \%$ respectively.

Table 2 and 3 shows that the three lime peel extract has antibacterial activity against $S$. aureus and E. coli, the greater loading extracts per disc, the greater diameter inhibition zones. Antibacterial activity from the lowest to the highest is dried peel ethanolic extract, dried peel ethyl acetate extract, and fresh peel ethyl acetate extract. Lime fruit peel extracts more actively inhibit $S$. aureus than E.coli.

Table 2. Antibacterial activity of lime fruit peel against $S$. aureus

\begin{tabular}{cccc}
\hline \multirow{2}{*}{$\begin{array}{c}\text { Loading } \\
\text { extract } \\
(\boldsymbol{\mu g} / \text { disc })\end{array}$} & $\begin{array}{c}\text { Inhibition zone diameter }(\mathbf{m m}) * \\
\text { extract }\end{array}$ & \multicolumn{2}{c}{ Ethyl acetate extract } \\
\cline { 2 - 4 } & Dried peel & Dried peel & $\begin{array}{c}\text { Fresh } \\
\text { peel }\end{array}$ \\
\hline 500 & $6,0 \pm 0,0$ & $6,0 \pm 0,0$ & $6,2 \pm 0,3$ \\
1000 & $6,0 \pm 0,0$ & $6,8 \pm 0,3$ & $7,0 \pm 0,0$ \\
2000 & $6,3 \pm 0,6$ & $7,8 \pm 0,3$ & $8,0 \pm 0,0$ \\
4000 & $8,5 \pm 0,5$ & $12,5 \pm 0,0$ & $14,3 \pm 0,3$ \\
Chloram- & $25,3 \pm 0,6$ & $25,3 \pm 0,6$ & $25,3 \pm 0,6$ \\
phenicol & $6,0 \pm 0,0$ & $6,0 \pm 0,0$ & $6,0 \pm 0,0$ \\
DMSO & 6,0 . & \\
\hline \multicolumn{4}{c}{$*$ included disc diameter $(6 \mathrm{~mm})$}
\end{tabular}

Table 3. Antibacterial activity of lime fruit peel against $E$. coli

\begin{tabular}{cccc}
\hline \multirow{2}{*}{$\begin{array}{c}\text { Loading } \\
\text { extract } \\
(\boldsymbol{\mu g} / \text { disc) }\end{array}$} & $\begin{array}{c}\text { Inhibition zone diameter }(\mathbf{m m}) * \\
\text { extract }\end{array}$ & Ethyl acetate extract \\
\cline { 2 - 4 } & Dried peel & Dried peel & Fresh peel \\
\hline 500 & $6,0 \pm 0,0$ & $6,0 \pm 0,0$ & $6,0 \pm 0,0$ \\
1000 & $6,0 \pm 0,0$ & $6,0 \pm 0,0$ & $6,8 \pm 0,3$ \\
2000 & $6,5 \pm 0,5$ & $6,8 \pm 0,8$ & $7,7 \pm 0,6$ \\
4000 & $6,8 \pm 0,8$ & $8,2 \pm 0,3$ & $9,5 \pm 0,5$ \\
Chloram- & $26,0 \pm 0,0$ & $25,3 \pm 0,6$ & $25,3 \pm 0,6$ \\
phenicol & & & \\
DMSO & $6,0 \pm 0,0$ & $6,0 \pm 0,0$ & $6,0 \pm 0,0$ \\
\hline \multicolumn{4}{c}{$*$ included disc diameter $(6 \mathrm{~mm})$}
\end{tabular}

These results are similar to results Chanthaphon et al. (2008) which states that the ethyl acetate extract of fresh lime fruit peel more active against Gram-positive bacteria than Gram-negative bacteria; antibacterial activity of ethyl acetate extract of fresh lime fruit peel to S.aureus larger than dried peel extract. This indicates the loss of certain antibacterial compounds during the drying process, especially volatile compounds. Aibinu et al. (2007) have proven that lime fruit peel essential oil also has antibacterial activity.

Ethyl acetate extract more active antibacterial than ethanolic extract because of 
less polar compound, such as coumarins and furanocoumarins which have antibacterial activity. Meranzin hydrate (coumarin) and oxypeucedanin hydrate (furanocoumarin) were isolated from ethyl acetate extract of flavedo Citrus grandis Osbeck. fruit from Japan has antibacterial activity against S.aureus with MIC $0.75 \mathrm{mg} / \mathrm{ml}$ and $0.24 \mathrm{mg} /$ $\mathrm{ml}$ (Mokbel et al., 2006).

Extracts are more active inhibit S.aureus than E. coli, possibly because E.coli (Gram negative bacteria) have the outer membrane lipopolysaccharide that limiting diffusion of hydrophobic compounds so E. coli are less sensitive to plants antibacterial (Tajkarimi et al., 2010).

\section{Conclusion}

The optimal condition to extract antibacterial compounds from lime fruit peel was using fresh peel with ethyl acetate as solvent. Ethyl acetate extract of fresh peel was more active against $S$.aureus than $E$. coli.

\section{References}

Agocs, A., Nagy, V., Szabo, Z., Mark, L., Ohmacht, R., \& Deli, J., 2007, Comparative Study on the Carotenoid Composition of the Peel and the Pulp of Different Citrus Species, Innovative Food Science and Emerging Technologies, 8, 390-394.

Aibinu, I., Adenipekun, T., Adelowotan, T., Ogunsanya, T., \& Odugbemi, T., 2007, Evaluation of the Antimicrobial Properties of Different Parts of Citrus Aurantifolia (Lime Fruit) as Used Locally, Afr. J. Trad. CAM, 4 (2), 185-190.

Bates, R.P., Morris, J.R., \& Crandall, P.G., 2001, Principles and Practices of Small- and MediumScale Fruit Juice Processing, FAO Agricultural Services Bulletin, 146, 115, 132-133.

Bocco, A., Cuvelier, M.E., Richrad, H., \& Berset, C., 1998, Antioxidant Activity and Phenolic Composition of Citrus Peel and Seed Extracts, J. Agric. Food Chem., 46, 2123-2129.

Chamblee, T.S., Karelitz, T., Radford, T., \& Clark, B.C., 1997, Identification of Sesquiterpenes in Citrus Essential Oils by Cryofocussing GC/FT-IR, Journal of Essential Oil Research, 9, $127-132$.

Chanthaphon, S., Chanthachum, S., \& Hongpattarakere, T., 2008, Antimicrobial Activities of Essential Oils and Crude Extracts from Tropical Citrus spp. Against Food-Related Microorganisms, Songklanakarin J. Sci. Technol., 30 (1), 125-131.

Dugo, P., Piperno, A., Romeo, R., Cambria, M., Russo, M., Carnovale, C., \& Mondello, L., 2009, Determination of Oxygen Heterocyclic Components in Citrus Products by HPLC with UV Detection, J. Agric. Food Chem., 57 (15), 6543-6551.

Li, B.B., Smith, B., \& Hossain, M.M., 2006, Extraction of Phenolics from Citrus Peels (I. Solvent Extraction Method), Separation and Purification Technology, 48, 182-188.

Mandalari, G., Bennett, R.N., Bisignano, G., Trombetta, D., Saija, A., Faulds, C.B., \& Gasson, M.J., 2007, Antimicrobial Activity of Flavonoids Extracted from Bergamot (Citrus bergamia Risso) Peel, a Byproduct of the Essential Oil Industry, Journal of Applied Microbiology, 103, 2056-2064.

May, C.D., 1990, Industrial Pectins : Sources, Production, and Applications, Carbohydr. Polym., 12, 79-99.

Mokbel, M.S., Watanabe, Y., Hashinaga, F., \& Suganuma, T., 2006, Purification of the Antioxidant and Antimicrobial Substance of Ethyl Acetate Extracts from Buntan (Citrus 
grandis Osbeck) Fruit Peel, Pak. J. Biol. Sci., 9 (1), 145-150.

Morton, J., 1987, Mexican Lime in Fruits of Warm Climates, Morton J.F., Miami.

Mujahid, R., 2011, Pemilihan Metode Analisis Flavonoid secara Spektroskopi UV-Vis serta Penerapannya pada Seledri (Apium graviolens L.), Murbei (Morus alba L.), Patikan Kebo (Euphorbia hirta L.) dan Jeruk Nipis (Citrus Aurantifolia), Tesis, 70, Pascasarjana Ilmu Farmasi, Fakultas Farmasi Universitas Gadjah Mada, Yogyakarta.

Nogata, Y., Sakamoto, K., Shiratsuchi, H., Ishii, T., Yano, M., \& Ohta, H., 2006, Flavonoid Composition of Fruit Tissues of Citrus Species, Biosci. Biotechnol. Biochem., 70 (1), 178-192.

Tajkarimi, M.M., Ibrahim, S.A., \& Cliver, D.O., 2010, Review : Antimicrobial Herb and Spice Compounds in Food, Food Control, 21, 1199-1218.

Wanger, A., 2007, Disk Diffusion Test and Gradient Methodologies, dalam Schwalbe, R., SteeleMoore, L., \& Goodwin, A.C. (Eds.), Antimicrobial Susceptibility Testing Protocols, 5365, CRC Press, London. 